\title{
Outcomes from Building Transparency in Governance in a Smart City Project in India: A Case Study of Panaji, Goa
}

\author{
By Mridula Goel ${ }^{*} \&$ Sheetal Thomas ${ }^{ \pm}$
}

\begin{abstract}
The Government of India is trying to tackle the challenges of rapid urbanization through the Smart Cities Mission, launched in 2015. This paper discusses a case about the development of a smart city under this initiative, which exhibits exemplary governance practices while improving developing infrastructure and technological solutions to solve critical problems of the city, e.g., Solid Waste Management. It addresses the question whether building good governance practices results in successful achievements of a public policy program and aimed at infrastructure development along with best practices in governance. This paper attempts to assess whether the Panaji Smart city project is in line with purpose of the Smart Cities Mission 'to create model cities which can be triggers for planned and rapid urban development on desired lines'. Information for the case study was collected through published data and personal site visits, interviews and discussions with senior officials of the project team and stakeholders. The findings are useful not only in portraying the Smart City of Panaji with respect to citizen engagement, transparency and accountability but also in evaluating the outcomes of the project. It is interesting to note that the "model" framework adopted to implement the project appears to be filled with good governance but has till date not made much impact on lives of residents of the smart city and as yet does not appear to be creating desired networks that would be connecting to urbanization in the region.
\end{abstract}

JEL Codes: G30

Keywords: engagement, governance, smart city, technology, transparency

\section{Introduction - Designing Cities to Tackle the Challenges of Rapid Urbanization}

India's Gross Domestic Product (GDP) has been steadily increasing, showing an annual growth of more than $7 \%$. This increase has placed India into the fast paced developing countries of the world, but this economic growth is challenged with ever increasing population. In 2014, the population of India's Cities was 410 million and as per the world urbanization report it is likely to reach to 600 million by 2030 and grow to 800 million in another 20 years (United Nations 2015). Thus, $40 \%$ to $50 \%$ of India's population will be residing in urban cities of India by 2030 and 2050 respectively.

${ }^{*}$ Associate Professor, Birla Institute of Technology \& Science, India.
${ }^{ \pm}$Doctoral Fellow, Birla Institute of Technology \& Science, India. 
Currently almost $30 \%$ of India's population lives in urban cities and contributes $63 \%$ of India's GDP (Office of the Registrar General \& Census Commissioner, India 2011). With increasing urbanization, the urban population will contribute 75\% of India's GDP by 2030 (World Bank 2011). As the degree of urbanization has grown, the needs of providing critical infrastructure to the growing urban population have also increased (The Statistics Portal 2018).

India has, however, not been able to effectively tap on the development potential of its urbanisation process as the existing urban infrastructure is not adequate to accommodate the extensive growth of its cities. The problem of rapid urbanization, which is not supported with suitable infrastructural developments, tends to create negative externalities even in the rural areas. It is expected that almost 25-30 persons from rural areas move every 60 seconds to major cities in India for better economic opportunities (Vajda 2017). The problem is compounded by a proliferation of informal settlements (slums) in urban areas. It is important to take care of these issues; otherwise India's cities will become increasingly chaotic and difficult to manage (Phua 2007). Furthermore, rural poverty will simply be converted to urban poverty, with little improvement in standards of living (Planning Commission Government of India 2013).

Consistently high population growth and rural-urban migration have posed serious challenges of urbanization in the country. As cities sprang up and expanded on a need basis they contributed to growing urban problems of congestion, sanitation, lack of access to basic amenities and overall poor quality of life. To combat this and to create "drivers of change" the government has set up the 'Smart Cities Mission' to create model cities which can be triggers for planned and rapid urban development on desired lines. Government of India has taken up with urgency the ever increasing needs of urbanization and launched the Atal Mission for Rejuvenation and Urban Transformation (AMRUT) Mission and the "100 Smart Cities" program in June 2015 to support the process of urbanization (Tripathi 2018). These initiatives aim to stimulate the State governments and Urban Local Bodies (ULBs) to implement the urban sector reforms. Ultimately, the restructured and enriched governance in cities would sustain the urban transformation.

The AMRUT Cities Program aims to enhance the basic infrastructure (water, sanitation, open spaces and public transportation) of 500 cities in India, with the Government of India looking to invest $\$ 7.5$ billion over next four years. The Program intends to provide suitable training to members of the urban local bodies (Charles 2015). On the other hand, under the "100 Smart Cities Mission" Program the government is committed to develop satellite towns of larger cities and modernize existing midsized cities. Within the framework of the Program, the aim is to pursue such information and communication technology (ICT) initiatives that improve livability, investment and service opportunities, and facilitate the achievement of growth in an environmentally sustainable manner (Vajda 2017).

The Indian Central Government has committed INR 480 billion $(\sim 6$ billion Euros) to finance the Smart Cities Mission, with a condition that the State Government should also spend an equivalent amount for the smart city project (Hoelscher 2015). This core funding is supposed to attract funds from other 
sources, including domestic and foreign private investors, development banks and bilateral donors.

Smart Cities need smart governance and smart regulation (Dewi Mutiara 2018) and urgent reforms are required at the institutional and policy level in order to ensure that these Programs do not fall victim to the errors of the past. Our study attempts to analyze whether adoption of new governance models, incorporating transparency in institutional processes in case of a smart city project, has helped to achieve desired outcomes of the public policy program (Babita Jangra 2016) of urban transformation in India.

\section{Concept of a Smart City}

An extensive literature review points out to the following definitions, processes and challenges of the smart city initiative taken up by Government of India. Paolo Neirotti et al. (2014) has identified the importance of smart use of technology to provide improved services to the citizens and thus improve their life quality. A smart city is one which has the potential to incorporate and efficiently use the latest technology to provide better services (Paolo Neirotti 2014). "A smart city is a system of systems - water, power, transportation, emergency response, built environment, etc. - with each one affecting all the others" (Pratap Podode 2016). During the last twenty years, the world has emerged as a competitive stage to usher developments into its cities, countries have come out to improve their infrastructures, providing the best services concerning environment, social and economic conditions (Freeman 2017).

These efforts brought up the concept of intelligent cities (Komninos 2009) that is the predecessor of Smart Cities (Yigitcanlar 2015). According to Mark Deakin and Al Waer, Smart Cities are those which are made up by intelligent usage of latest information technology, in areas like health management, transportation and mobility, use of efficient power and energy, knowledge creation and knowledge transfer in terms of education and local governance (Mark Deakin and Al Waer 2011). Camboim et al. 2019 studied the development of several smart cities in Europe like Amsterdam, Barcelona, Lisbon, Vienna and conceptualized a smart city as an urban innovation ecosystem, where knowledge easily flows among different stakeholders to create value, supported by suitable institutions and governance, a digital-green infrastructure and urban planning to provide various facilities according to functional requirements (Camboim et al. 2019).

According to the Smart Cities Council, a smart city is one that uses information and communications technology (ICT) to create a more livable and sustainable urban environment. The Smart City approach is not "one-size-fits-all"; each city assesses local resource availability and strengths and identifies its priorities to formulate its own concept, vision, mission and plan (proposal) for development.

The Urban Development and Services initiative of the World Economic Forum helps governments to address major urban challenges. In 2015, their focus was on India (World Economic Forum 2015). They provided recommendations 
that focused on institutional reforms to accelerate the delivery of Smart Cities and support urban development. Their recommendations included strengthening city administration, putting suitable user charges for service delivery, while stipulating that subsidized user costs should be funded by the state, helping to ensure the financial independence of the city. They recommended collaborating with the private sector and improving the system of resolution of disputes, good citizen engagement and feedback mechanisms and improving the permit process. India's three tier governance structure, Central, State and local, often involves liaising with multiple departments. This makes obtaining permits a lengthy process, but several state governments have enacted reforms to optimize the process. Goa has also, done so in 2019.

The Urban Development and Services initiative stated that by developing Smart Cities, countries will create a welcoming environment for foreign investment flows, resulting in industrial growth and higher GDP. Smart solutions in key areas of environmental protection, health, transport and waste management can contribute to sustainable growth and better quality of life. It is forecast that a smart city project may generate a $10-15 \%$ rise in employment, especially jobs in information technology and information systems (Tata Communications 2018).

The focus on smart city development as a way to urbanize in an efficient manner is a strategy that has also, been adopted in other places of the world. Smart City concept is on the agenda of countries such as UK (Caprotti 2016), Singapore (Sang Keon Lee 2016), Spain (Martín García Vaquero 2016) and many others. The development of automation devices for smart homes supports the development of smart cities and these in turn create infrastructure that creates effective use of smart home devices (Yi 2013). Smart technology can even be an important part of the solution to city food challenges (Maye 2019) but perhaps it is more important for developing countries like India. Developing nations face greater exacerbated challenges of urbanization such as lack of infrastructure, population growth in urban areas, poor urban services such as drinking water, sanitation, health or education.

Spearheading urbanization through smart city concept has nuances of the Chinese strategy of using SEZs to lead development in the country. The infrastructural development in these SEZs showcased the intensive modernization and growth of the region. It enabled the growth of manufacturing led development process (Frick et al. 2019, Madakufamba 2015). As in case of China the success factors for India also include a resilient commitment for transformation from the country's top leadership, favorable policies and regulations, autonomy to institutions that encourage them to take developmental steps, along with strong support of Government (Zeng 2012). 


\section{Channelizing Development through Decentralized Governance Mechanisms}

However, in a country as vast and diverse like India, in terms of geography and people, the understanding and connect of policy requires reaching to the grassroots. Realizing the need to decentralize and gain advantage of closer interaction and better accountability between public and government, there is considerable emphasis on reviving and/or strengthening local institutions and mechanisms.

To strengthen local governance in the rural areas, the $73^{\text {rd }}$ Constitutional Amendment in 1992 was carried out to give Constitutional status to the Panchayats"1 $^{1}$ as institutions of local governance for promoting economic development by strengthening local governance at the rural level (Ananth 2014). The Panchayati Raj Institution (PRI) is government by itself and acts as an agency of the state government (Tame 2014). The objective of PRIs is to understand the problems at the ground level and put in place both acceptable and feasible solutions. However, in the urban areas such functions are done by the urban local bodies (ULB), the municipalities and city corporations, which have been operating to tackle common problems in their municipality, using traditional mechanisms that prioritize according to expression of public need and grievance.

The nature of administration depends on severity or impact of the problem. For instance while fighting the high level of air pollution in the Indian capital, the Delhi government authorities hiked the parking fees by four times to dissuade people from use of private cars and thereby reduce vehicular emissions (Karelia 2017).

To rationalize local government functioning in the urban areas the government through the $74^{\text {th }}$ Constitutional Amendment of 1992, attempted to decentralize urban governance by entrusting power to the ULB (Hussain 2007). Yet, the negative public perception about ULBs functioning mechanisms is so deep rooted that such amendments and other directives fail to create a positive impact.

The Smart Cities Mission is based on 'bottom-up' methodology. Processes, proposals and projects are conceptualized locally through early citizen stakeholder engagement. This is in line with Government of India's commitment not only to build inclusive and livable cities but also to fulfill its vision of achieving more decentralized and collaborative decision-making (Hoelscher 2015).

One fundamental objective of the 100 Smart Cities scheme is to reinforce the ULBs' capability to create cash for themselves through user costs, as the smart city has its own independent identity that is free of the perception about existing municipalities and city corporations (Gordon Falconer 2012). However, service delivery institutions often suffer from limited autonomy, accountability and incentives, and an overall lack of consumer focus. This makes it difficult for them to recover user costs.

Along with such limitations faced by ULBs, there are problems created by deep-rooted corrupt practices in several places. Use of latest technological

\footnotetext{
${ }^{1}$ Panchayats are an elective council of about five members organized in the Republic of India as an organ of village self-government.
} 
developments in the working of municipal corporations is low, not only due to limited access to funds but also more often due to traditional, well entrenched bureaucratic systems.

Thus, some features that should be present in a smart city include:

- Development of city into a urban hub with best infrastructural amenities

- Focused approach to bring inclusiveness in social and economic conditions

- Planned long term growth strategy

- Use of technology to enhance governance and administrative efficiency

- Sustainable development and livable environment

In our discussion of the case of Smart City development of Panaji, we attempt to assess the presence of the above features. It is important to know whether the adoption of smart city measures the city has created employment, implemented sustainability of public policy projects and above all has it been able to promote the key objective of the Smart Cities Mission : as "driver of change" that can then be a trigger for planned and rapid urban development on desired lines.

\section{Methodology}

The paper aims to assess the developments in governance, infrastructure and technology under Smart City initiative, these discussions are presented in the form of a case. The data was collected through both primary and secondary sources; primary data was obtained by meeting different officials and employees directly engaged with activities under Smart City Project. Interview method was used to understand and extract relevant information related to practices and governance styles of smart city initiative. Observation method was used to identify the benefits of smart city initiative on infrastructure and technology along with published data available through government body. The secondary data was also collected from newspapers apart from government publications like tenders, agenda's, detailed project reports, and focused group discussion transcripts.

\section{A Case Study of Panaji as a Smart City}

The Government selects cities in India as part of the Smart Cities Mission through a "City Challenge Competition", which creates identity association and bonding for the local community. The public, the ULBs and state government work as one team to apply for the competitive process and get the resource support, they then have a more developed sense of ownership of the program and related projects.

The Smart Cities Mission objective is to develop at least two Smart Cities in each of 29 states of India, where cities with a population of over 1 million may become potential Smart Cities; besides which State capitals, cultural heritage cities and the agglomerates of cities are also, considered to have the potential to be Smart Cities. The focus of the Smart City Mission is on sustainable and inclusive 
development and the idea is to look at compact areas, with the objective of creating a replicable model which will act like a light house to other aspiring cities.

The selection of Panaji fit the choice criterion on account of being a State capital and a cultural heritage city. There are close to 900 heritage structures in and around Panaji, as per the statistics revealed by the Goa heritage action group (Heritage Conservation Phase 1- Listing and grading of heritage structures in Panaji 2014). The population of the city is, however, only 114,759 persons in the metropolitan area as per 2011 Census of India (Provisional Population Totals, 2011) (Office of the Registrar General \& Census Commissioner, India 2011). Also, it is a compact area and its development can be 'with the objective of creating a replicable model which will act like a light house to other aspiring cities'.

\section{Key Priorities of Smart City Development}

An interaction of the goals of Smart Cities Mission along with requirements and priorities of the state of Goa on the one hand and the desired objectives for Panaji as gathered through citizen engagement, determined the focus areas for implementation (Figure 1).

As per the Smart Cities Mission, Smart Cities should contain at least one pancity feature. The idea is to incorporate 'smart planning' in infrastructure for enhancing inclusiveness and creating better environmental outcomes (Kok Siew $\mathrm{Ng}$ 2019). In case of Panaji, Intelligent Transport System for Eco Mobility and Information Communication Technology (ICT) enabled Municipal Services have been identified as two priority areas for intervention on a city wide basis. Our focus is on studying the latter: Use of ICT to improve service delivery with respect to solid waste management (SWM) in case of the smart city of Panaji.

Solid waste management in India is largely inefficient and ineffective, due largely to the absence of a sustainable business model covering the full spectrum of waste management activities (Annepu 2012, Rajkumar Joshi 2016, Harshit Khandelwal 2019). In case of Goa, and most other states in India, the problem exists right from inadequate coverage of waste collection, to segregation and right down to the fact that collected waste is rarely disposed of in a controlled, hygienic and environmentally sensitive way.

To tackle this situation the model SWM plant in Saligao was set up on May 30, 2015, even before the selection of Panaji as a smart city. The SWM plant is 9 kms from Panaji and had started generating electricity for captive use in just seven months of set up (The Times of India, Saligao Garbage Treatment Plant begins generating power 2017).

Municipal service level benchmarks in the city of Panaji already indicated robust service provision in the basic sectors - water supply, waste water, solid waste management and storm drainage. The focus after the smart city project was on improving the efficacy and efficiency of these systems. It is therefore proposed to upgrade the quality and levels of municipal service delivery through process reengineering and embedding of ICT solutions. RFID readers to monitor litter bin evacuation and GPS tracked waste transport vehicles will give the solid waste 
Vol. 7, No. 1 Goel \& Thomas: Outcomes from Building Transparency in Governance...

management cell the advantage of real-time and remote monitoring. Solid waste collection systems are well planned, but monitoring of these systems leaves much to be desired.

Figure 1. Factors Determining Panaji Smart City Objectives

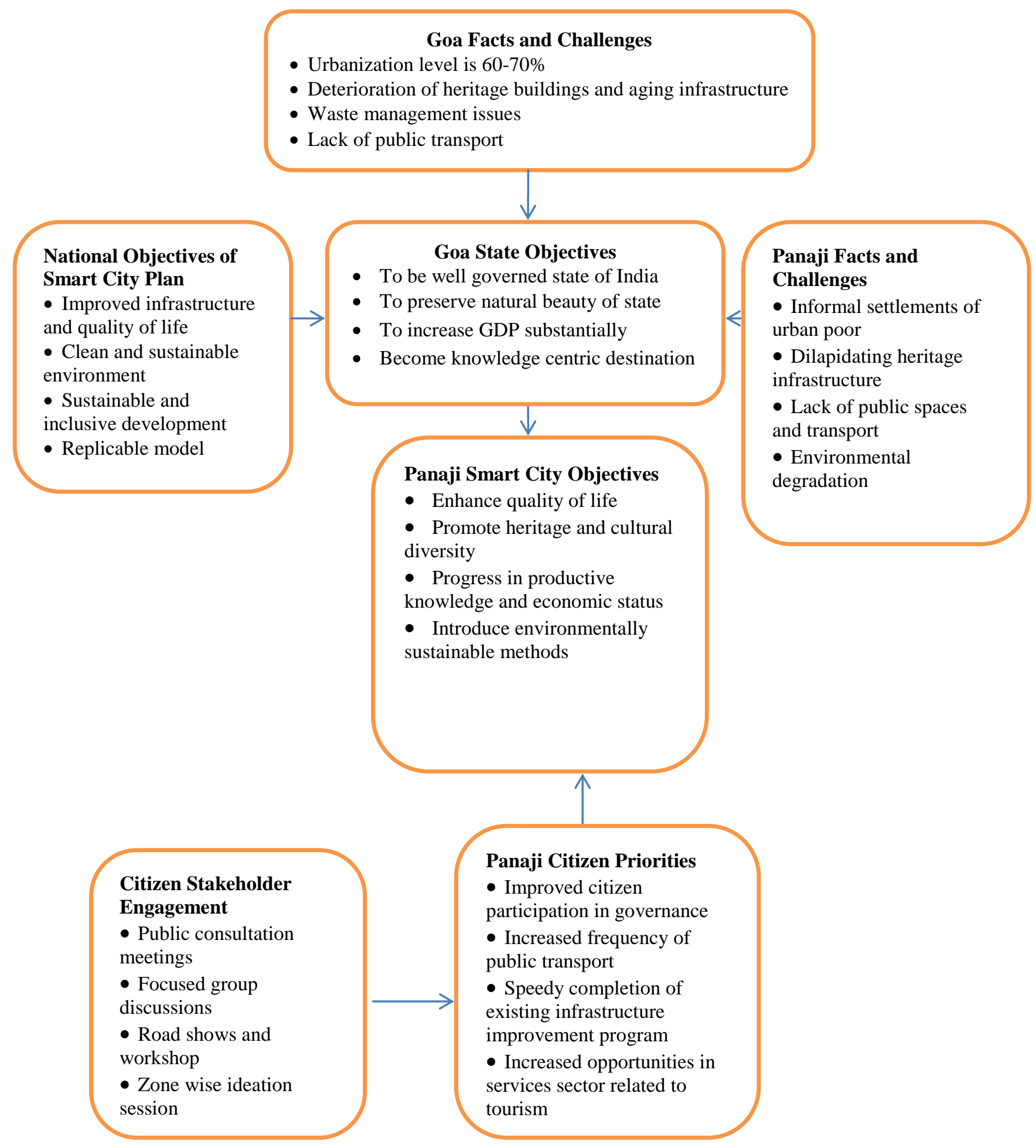

Source: Compiled by researchers from various sources. 
The story of waste management in Panaji is a best practice that is talked of in India and abroad. The effectiveness of waste management department in the municipal arm, the City Corporation of Panaji (CCP) is challenged by a dearth of adequate staff to monitor waste management. With system efficiencies being rolled in, Panaji can move towards the realization of its goal of a zero waste city.

Proposed e-governance measures enable linkage of these systems to city administration. Currently service provision in the city is through multiple departments. The e-governance platform will ensure a unified database for revenue and service provision. Data analytics possible through the proposed MIS system will enable informed decision making and have a significant bearing on city planning and citizen engagement. Given that the basic infrastructure was already in place, using technology to improve efficiency in SWM in Panaji was a low hanging fruit.

However, the development of smart cities is not only about making improvements within that city, but to also, create triggers for development in surrounding regions. Unfortunately, that appears to remain a challenge. The adoption of SWM systems, supported by ICT has yet failed to create desirable benefits for other parts of the state.

\section{Transparency at Central and State Government level}

Goa was one of the 23 states /UTs to have a second chance in "fast track" selection process and its capital city: Panaji was selected in this round. The Director (Smart Cities), Ministry of Urban development shared some observations made by the Proposal Review Committee with the Principal Secretary (Urban Development) Goa Government. The extent of transparency in the process is obvious as this letter is available on the website of Panaji Smart City (Imagine Panaji Smart City Development Ltd. 2017) ${ }^{2}$.

For instance, one of the relevant suggestions from the Ministry related to municipal works and especially solid waste management (SWM), "the municipal services package attempts to fit in various services in a piecemeal manner. While the SWM subcomponent is relatively better worked out, components such as water meters and power grid seems loose and not integrated into the overall package". It was recommended vide this letter to revise the details and illustrate inter linkages within the sub-components or alternatively only focus on solid waste management aspects (Imagine Panaji Smart City Development Ltd. 2017). SWM continues to be an important priority for both the city's ULBs: Panaji Smart City and City Corporation of Panaji, but integrating with other utilities has yet to be completed. Further, the transfer of good practices to surrounding areas is missing. The network effects of smart city development to improve urbanization in the region do not appear to have occurred in our case.

\footnotetext{
${ }^{2}$ https://imaginepanaji.com/wp-content/uploads/2016/03/Comments-from-MOUD.pdf.
} 


\section{Efficient Institutional Mechanisms for Local Governance}

100 Smart Cities initiative of the Indian government rests on four pillars related to: Physical infrastructure, Social factors, Economic factors and Institutional features (Government of India - Smart City 2017). The physical factors relate to infrastructure in high linkage sectors like Transport, Power, Water, IT and the current globally challenging area of pollution and waste (Rita Yi Man Li 2015). Social factors relate to the areas of education and culture, as expected, but noteworthy is their emphasis on inclusive development. The economic pillar covers skill development and entrepreneurship, which is a new policy initiative of present government, financial institutions, etc. However, it is the challenges of establishing efficient institutions and processes in government that are known to be difficult.

It is noteworthy that on several of these institutional features and mechanisms the case of Smart City of Panaji has shown positive changes, even in the short span of two years of commencement of the project. We discuss in the following sections changes related to key institutional features like: minimum government, maximum governance, citizen engagement, transparency and accountability.

Such institutional reforms are very useful in economic development as it is the institutional factors that pose an important risk to foreign investment. To boost public and private sector growth within the country and to give a positive message to the foreign investors, it is important that we have consistent and effective regulatory policies. As the multinational organizations want to do business in environments which are market friendly, it is important the country regime is open to such overseas investors (Mumtaz Hussain Shah 2015). A study conducted by Valbona Zeneli confirmed that a strong and significant relationship existed between the quality of the reforms, the performance of the institutions in the host countries and the attraction and distribution of FDI in the region (Zeneli 2014). An improvement in governance can create substantial and constructive impact on the income level. Thus, development in institutional quality would increase the country's income level which has further positive effect on the level of foreign investment that comes into the country (Bissoon 2011).

\section{Minimum Government, Maximum Governance}

A Special Purpose Vehicle ${ }^{3}$ (SPV) will execute the implementation of the Smart City Action Plan. For Smart Cities, the government will appoint CEOs, thereby restricting the autonomy of local governments. It is these CEOs who will drive the concept and execution of the project. The Imagine Panaji Smart City Development Ltd (IPSCDL) was incorporated as a limited company under the Companies Act 2013 with the State Government and City Corporation of Panaji as equal promoters of the Special Purpose Vehicle (SPV): IPSCDL.

\footnotetext{
${ }^{3}$ A special purpose vehicle (SPV) in India is a limited company formed for a special purpose. These entities have powers limited to the execution of the specific purpose for which they have been formed, their life is limited to the completion of the purpose.
} 
Public policy initiatives are often managed through an SPV, as it is considered that an SPV brings independence and transparency to a project. Under the smart Cities Mission as well, it was stated that the SPV will be responsible for managing, operating, evaluating and reporting the Smart City development projects within their city. Panaji though selected after the first 20 selections in round 1 the 'fast track mode' as one of 13 cities, is the second smart city project, after Dharamshala ${ }^{4}$, to set up an SPV (The Times of India 2016).

Using an SPV brings in efficiency and speed in decision making and implementation. It also, enabled the IPSCDL team to maintain a clean image and reputation. For example, Municipal bonds which are identified by the government as a source of revenue to support funding for Smart Cities development have not yet been adopted in case of Smart City Panaji because of a fear of public negative perception (Royal HaskoningDHV 2015).

The organizational structure of the SPV in case of Panaji is designed for good governance. Taking along various layers of government has been facilitated through direct representation of each in the functioning of the SPV (Figure 2). The Chairman of IPSCDL is from the Ministry of Urban Development and the Managing director and CEO is from the State Government's Goa State Infrastructure Development Corporation (GSIDC). This covers representation from the Central and State levels of government. The GSIDC functions as the Project Management Unit (PMU) and provides technical staff to IPSCDL.

Figure 2. Smart City Implementation-Organizational Structure

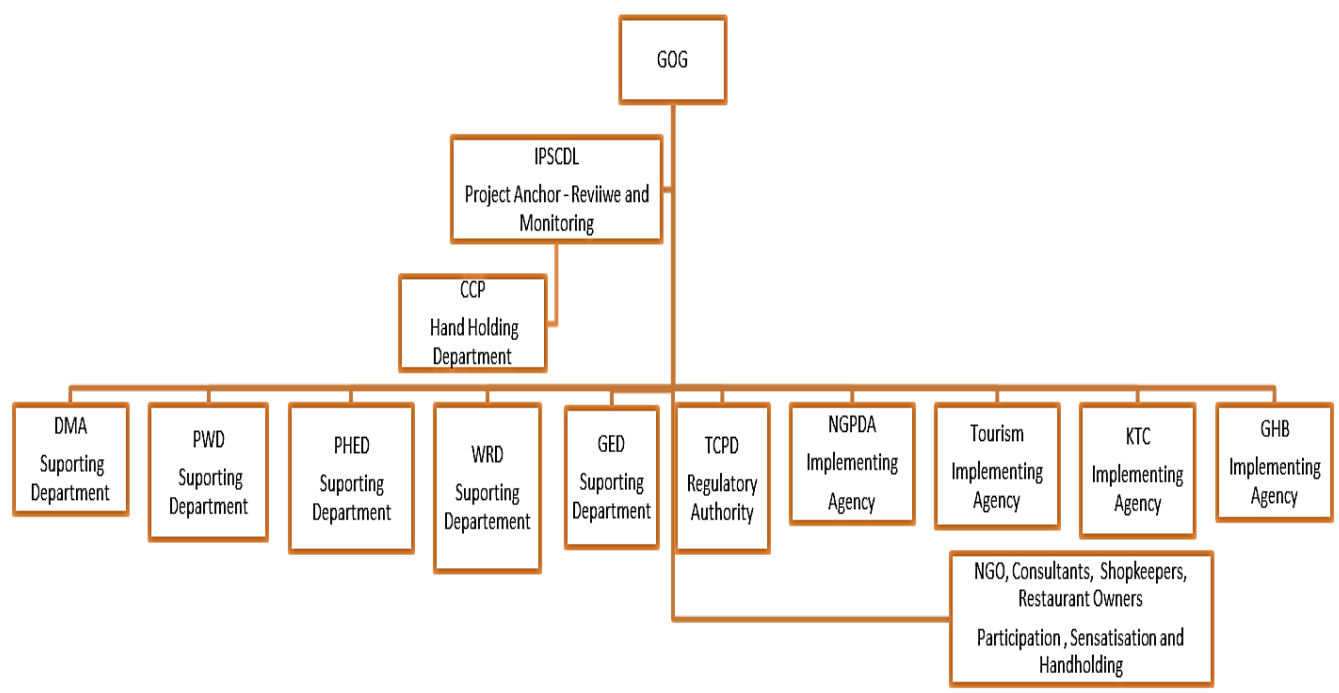

Source: Compiled by authors from inputs provided by IPSCDL, Panaji.

${ }^{4}$ Dharamshala is a city in the Indian state of Himachal Pradesh. Surrounded by cedar forests on the edge of the Himalayas. 
To ensure operational independence and autonomy in decision making of the SPV, the Goa State Level High Powered Steering Committee agreed, in principle, to empower the IPSCDL by delegating the rights and obligations of the ULBs: City Corporation of Panaji (CCP), North Goa Planning and Development Authority (NGPDA) and Goa State Urban Development Authority (GSUDA) to it.

The organizational Structure has representation from the different layers and departments that are required to implement the smart city initiatives. Further, the key thread that has bound the initiative and helped to manage conflict between the authorities has been the nature of leadership of the state. A strong and popular Chief Minister in the state helped to steer the program in a smooth manner. After his demise on 17 March, 2019 the impact on such a public policy program and its functioning would need to be re-assessed.

\section{Smart Functioning Office of Imagine Panaji Smart City Development Ltd.}

Transparency in governance is visible in case of the Smart City Office at Panaji. The governance style adopted by this Smart City office is very distinct from that commonly associated with government office ambience and functioning in the country. A visit by the authors to the Imagine Panaji Smart City Development Ltd project office was a revelation. The office premises are housed in the Adil Shah Palace ${ }^{5}$ which is located in the heart of the city. The sprawling high ceilinged rooms are spartanly furnished but well equipped with e-devices. There is a marked absence of the usual clutter found in most government offices in the country: in terms of storage cabinets, cupboards, files and papers.

All information asked for was searched in the laptops by the helpful staff. A unique feature was the presence of a floor printer with a box of used paper for reuse. Such a pool of used paper in a government office can be viewed as a clear sign of transparency! While most government departments hoard documents in confidential files and keep well locked in cabinets for decades, here was a government office easily putting out rejected paper for re-use.

The staff in the Imagine Panaji Smart City Development Ltd project office was refreshingly young and there were more women than men. The Managing director and CEO is in fact, less than 40 years of age. The team works cohesively and is committed to working long hours with enthusiasm.

It is however, notable that the commitment of the IPSCDL team and the independence of the SPV has yet not been able to make significant change in the lives of the residents of the Smart City of Panaji and definitely not created linkages of development in areas beyond the city.

\footnotetext{
${ }^{5}$ The palace of the Muslim ruler of Bijapur Yusuf Adil Shah (1450-1511), is the oldest surviving building in the city, the seat of Goan Secretariat (built around 1500). Typically colonial in design and architecture, the building once served as Adil Shah's summer palace cum fortress which has been renovated.
} 


\section{A Well-defined and Transparent Purchase Process}

In order to build the digital infrastructure required as per the concept of the Smart Cities Mission it was decided to put in place the Goa Intelligent City Management System (GICMS) in Panaji. The Smart City solutions in Goa will be integrated through an existing City Backbone Network and a Command and Control Centre is proposed to be set up at the IPSCDL office, Panaji.

The gamut of Smart City digital solutions includes city wide public Wi-Fi to cover access to information on the entire key services available for citizens through various apps (Ministry of Urban Development India 2016). Real time monitoring and tracking will be done for waste collection bins and collection vehicles, as mentioned earlier. Smart environmental sensors will be integrated with the Command and Control Centre to capture and display/provide feed on temperature, humidity, air pollution, noise pollution, etc. Smart parking facilities will be put in place to locate empty parking spaces and mobile app based bookings.

The Smart Cities Mission recommends that the executive wing of the city needs to develop technical and management capacity to execute large urban rejuvenation Programs. However, in case of identifying a vendor for the Goa Intelligent City Management System (GICMS) the technical specifications were prepared by the team at the IPSCDL project office. While the government allows for hiring a project management consultant for such and other functions of a project, this young team along with their Managing Director \& CEO handled the task on their own.

The process of tendering a key project is well defined so that bids can be comparable on technical grounds. The technical specifications for the project were posted to invite bids for tenders to finalize the vendor to operate under the Smart City Mission. IPSCDL ensured while creating the tender document that a proof of concept was a mandatory condition for technical qualification of the vendor. IPSCDL launched its proof of concept demonstrations for the short listed leading four bidders after the first stage of bid evaluation. Four companies: Bharat Sanchar Nigam Limited (BSNL), Honeywell International Inc., Larsen \& Toubro Ltd, and NEC Technologies India Private Limited were selected for the city surveillance trial.

The criteria was to ensure that the bidders who have so far projected themselves on paper are now putting up a live demonstration of their worth and commitment. Most reasons why a large government project fails are the lack of coordination and lack of the promised delivery on paper during the bid.

The four companies were required to conceptualize a full system, including a surveillance system along with a command and control center. They were then given independent scores based on performance. On basis of an overall technical score the financial bid was opened and the work order given to the lowest bidder on July $02,2018$.

Larsen \& Toubro Ltd., which is already doing similar work on other Smart city projects in the country beat BSNL, Honeywell and NEC by emerging as the lowest bidder with their bid of Rs 180 crore ( 22.8 million Euros). 
The letter of intent was issued to Larsen \& Toubro Ltd and the first phase of work has started. It covers laying of the optical fibre network, creation of Wi-Fi hotspots at key locations, setting up of the integrated command and control center. The command and control center will cover the entire city with 400-odd surveillance cameras, and will be integrated with the City Corporation of Panaji's garbage management system. It will help to inform the authorities over which areas garbage needs to be collected, which public bins are overflowing and residents through their smartphone app can also, know whether their garbage has been collected from their doorstep or not. "In this way, we want to increase the efficiency of municipal systems", said Commissioner of City Corporation of Panaji. The project is time bound and had to be completed in eight months, by February 2019. However, as of April 2019 the processes were not implemented. L\&T is in process of establishing the logistic infrastructure before starting operations. Mechanisms that incorporate transparency in purchase and ensuring quality at times result in unavoidable implementation delays.

\section{Citizen Stakeholder Engagement}

The state of Goa is often known in India as the "West of the East" (Sudhir Vyankatesh Wanmali 2018) and its citizens have a strong voice with the government and in community affairs. The Smart Cities project of the capital city is close to the hearts of the people of Goa and the media avidly follows and freely reports on the developments therein.

In the Smart Cities Mission one of the key criterion is citizen engagement, and in Goa citizen stakeholder engagement is usually intense. In case of the Smart City Panaji the public involvement has been very strong both at the stage of concept development, proposal preparation and finalization. The City Corporation of Panaji, the relevant municipality, engaged with citizens across various platforms to gather suggestions and feedback towards the smart development of Panaji City. This included public consultation meetings and focus group discussions with stakeholders, road shows, workshops and zone wise ideation sessions. Some of the key areas discussed were Transport \& Mobility, Heritage and Waste Management.

Consultations with citizens brought forth concerns of a deteriorating heritage due to factors related to development restrictions on conservation zone, lack of enforcement powers with Heritage Committee and lack of funds with owners to maintain heritage structures. Citizens expressed environmental concerns related to higher pollution emissions and adverse effect on the ecology of water bodies and even Panaji's prime hilly area of Altinho, which houses key government offices and Chief Minister of Goa's residence.

Events like celebrity meets, musical programs etc. were organized to promote and sensitize the local people even prior to the submission of Smart city proposal to the competition. Team FC Goa (Indian Super League, Football team) made an appearance to engage with the community, raise awareness and show its support for the Panaji Smart City Challenge. The Bandstand, a community event was organized by Confederation of Indian Industry (CII), Goa Chapter and the City 
Corporation of Panaji every Sunday evening to promote Panaji Smart City's initiative for citizen involvement.

CII also, collaborated with the Corporation of the City of Panaji, to organize a Panaji Smart City Round Table to discuss global experiences and solutions. A technical exhibition was arranged wherein proposed maps were displayed and explained to the general public, in order to gather feedback from stakeholders. Focus group discussions, press conferences, public consultation meetings were regularly organized to gather support of the community.

While such engagement was carried out in the preparatory stages and in the initial stage of implementation of the smart city project, it does not appear to be the case at this time. This is supported by the feedback gathered from residents given below.

A similar situation prevails with respect to media reporting and public communication through IPSCDL website.

\section{Panaji Smart City Project Outcomes}

Media reporting is an important source for assessing transparency and accountability. While information was freely available to the authors from the staff at IPSCDL project office but the best reference sources they had to offer us were the published media reports in local newspapers. Besides their website, which displays all documents and processes till award of the project there are the newspaper releases for most developments after receiving the Smart City status. The media coverage is regular and comprehensive and possibly explains why the Smart City developments are not updated on their own website. At best links to media reports are provided on the site. Hence, for purpose of this case for all developments post selection of Panaji as a Smart City we have referred to press releases in local newspapers.

However, updating of activities and progress of Smart City Projects on own website is important and necessary to maintain the quality of communication with the public. It is observed that the website is not updated for long and as the project has progressed without making big, visible changes the media coverage appears to be also slow in recent times.

As the phase wise implementation of various schemes and programs related to smart city project is going on, interviews and discussions with residents of Panaji were carried out to understand ground level realities during the period from January 2018 to January 2019. Issues of governance, technological advancements and effective solid waste management were discussed and some of the observations gathered were in contradiction to the initial stance of: active Citizen engagement and open communication.

During the implementation phase, gaps in communication were reported by the residents; the Smart City planning had emphasized on transparency in understanding the needs of resident citizens and detailed maps and plans were publicly shared, as indicated above. However, as conveyed to authors such maps are not easily accessible in public domain any longer. The implementing authorities need to be careful to sustain their initial stance of communicating 
information easily to the stakeholders and maintaining citizen engagement even during the implementation phase.

The garbage management system is being run efficiently along with local municipal bodies like the CCP and there is a visible improvement in cleanliness of the city as result. However, citizens expressed reservation about the operational sustainability of the projects that form the smart city development as "user charges" recommended for sustainability have not been incorporated. Until many of the projects roll out such outcomes cannot be commented upon. However, on speaking to IPSCDL office it was learnt that in most cases operational maintenance costs have been built onto the L\&T project

Citizens appreciated the beautification and cleanliness of the main spine of the city but were not satisfied with the overall image of the city. They felt that while the Smart Cities Mission envisaged creating livable urban spaces leading to improvement in quality of life of its residents such change was yet to happen. Further, a key objective of the Smart Cities Mission is to bring inclusiveness in social and economic conditions of the people in the region. Herein residents stated that the project did not communicate the employment and income generation possibilities for residents. It is true that smart city developments will add to increase in land value through creating prospects of capital gains, but many residents are not satisfied with the outcomes of the investment in Panaji Smart City development as the revenue generation or employment creation in the current period is not visible.

\section{Conclusion}

Urbanization is a natural outcome of economic growth. The pace of the process of urbanization in a country with both a large and rapidly growing population is bound to present both infrastructural and governance challenges. This is more so when the government of the country adopts policies to speed up the growth in manufacturing output (Mridula Goel 2017). The Make in India policy is bound to step up the migration of workers from rural to urban areas.

The Smart Cities Mission is an important initiative towards developing infrastructure in urban spaces in a planned way and addressing key priorities using technological solutions. The present study of the capital city of the state of Goa, best known as a popular tourist destination, offers a view of the important changes in the institutional features and mechanisms that have been identified as one of the important pillars to support urban development. Implementation and governance of the Smart City Program in Panaji exhibited the exemplary practices related to stakeholder engagement and transparency and accountability in governance. However, as the implementation of the project is proceeding there appears to be some dissonance; perceived through poor media coverage, lack of website updation of activities and progress and citizen perception. Further, the nature of the program does not incorporate any explicit, recognizable mechanisms to spread good practices. Even the specific achievements of good practices in SWM adopted in Panaji have failed to impact surrounding areas. Explicit policy directives by the 
state government are required and proposed in the last year for this purpose. This begets the question of how strong the network effects of smart city development are likely to be in encouraging regional urban transformation. The questions thus, that remain to be addressed are:

- How important is the design of a public policy program in achieving its goal? Is the Smart Cities Mission designed suitably for urban transformation?

- Can governance reforms overcome the barriers of long gestation period in infrastructural development to create efficient outcomes?

- Can digitization be an adequate process improvement to tackle the challenges of urban development?

\section{References}

Ananth P (2014) Panchayati Raj in India. Journal of Education \& Social Policy 1(1): 1-9. Annepu RK (2012) Sustainable solid waste management in India. New York: Columbia University in the City of New York.

Babita Jangra JM (2016) Swachh bharat abhiyan (clean India mission): SWOT analysis. International Journal of Community Medicine and Public Health 3(12): 3285-3290.

Bissoon O (2011) Can better institutions attract more foreign direct investment (FDI)? Evidence from developing countries. In International Conference on Applied Economics - ICOAE, 59-70.

Camboim GF, Zawislak PA, Pufal NA (2019) Driving elements to make cities smarter: evidences from European projects. Technological Forecasting and Social Change 142(May): 154-167.

Caprotti FCR (2016) Smart-eco cities in the UK: trends and city profiles. Exeter, UK: University of Exeter (SMART-ECO Project).

Charles Correa Foundation - CCF (2014) Heritage conservation phase 1- Listing and grading of heritage structures in Panaji. Panaji: CCF.

Charles A (2015) How can India make smart cities a reality? Retrieved from: https://www.weforum.org/agenda/2015/11/ how-can-india-ma ke-smart-cities-areality/. [Accessed 18 June 2018]

Dewi Mutiara SY (2018) Smart governance for smart city. IOP Conference Series: Earth and Environmental Science.

Freeman G (2017) The origin and implementation of the smart-Sustainable city conceptthe case of Malmö, Sweden. Master Thesis. Lund, Sweden: The International Institute for Industrial Environmental Economics, Lund University.

Frick SA, Rodriguez-Pose A, Wong MD (2019) Toward economically dynamic special economic zones in emerging countries. Economic Geography 29(1): 30-64.

Gordon Falconer SM (2012) Smart city framework: a systematic process for enabling smart+connected communities. Cisco Point of View, 2-9.

Government of India - Smart City (2017) What is a smart city. Retrieved from: http://smartcities. gov.in/content/innerpage/what-is-smart-city.php. [Accessed 20 May 2018] 
Harshit Khandelwal HD (2019) Application of life cycle assessment in municipal solid waste management: a worldwide critical review. Journal of Cleaner Production 209(Feb): 630-654.

Hoelscher RA (2015) India's smart cities mission: an assessment. ORF Issue Brief (124): $1-11$.

Hussain MA (2007) Urban governance and politics: a case study of Tirupati. The Indian Journal of Political Science 68(3): 509-522.

Imagine Panaji Smart City Development Ltd. (2017) Retrieved from: https://imaginepanaji.com/wp-content/uploads/2016/03/Comments-fromMOUD.pdf. [Accessed 16 June 2018]

Karelia G (2017) 7 steps taken by authorities to curb rising air pollution levels In Delhi. S Bhaskar (ed.) Retrieved from: https://swachhindia.ndtv. com/7-steps-taken-byauthorities-to-curb-rising-air-pollution-levels-in-delhi-14332/. [Accessed 26 June 2018]

Kok Siew Ng AY (2019) Sustainable waste management through synergistic utilisation of commercial and domestic organic waste for efficient resource recovery and valorisation in the UK. Journal of Cleaner Production 277(Aug): 248-262.

Komninos N (2009) Intelligent cities: towards interactive and global innovation environments. International Journal of Innovation and Regional Development 1(4): $337-355$.

Madakufamba M (2015) The role of special economic zones in China's development Prospects for Africa. Southern African News Features.

Mark Deakin HA, Al Waer H (2011) From intelligent to smart cities. Intelligent Buildings International 3(3): 140-152.

Martín García Vaquero JM-A (2016) Smart cities in Spain - Policy, sustainability, and the national plan: new political measures, agents, and sustainability. In Economic Modeling Analysis and Policy for Sustainability, 266-283. IGI Global.

Maye D (2019) Smart food city': conceptual relations between smart city planning, urban food systems and innovation theory. City, Culture and Society 16(Mar): 18-27.

Ministry of Urban Development India (2016) Smart city proposal - Panjim. Retrieved from: https://imagi nepanaji.com/wp-content/uploads/2016/03/Panaji-Smart-CityProposal.pdf. [Accessed 29 June 2018]

Mridula Goel MA (2017) Make in India Policy of 2014 and the self reliance objective of the 1956 industrial policy. International Journal of Research in Computer application and Management 7(1): 24-17.

Mumtaz Hussain Shah AG (2015). Significance of Good Governance for FDI Inflows in SAARC Countries. Business \& Economic Review 7(2): 31-52.

Office of the Registrar General \& Census Commissioner, India (2011) Retrieved from: http://www.censusindia.gov.in/2011census/dchb/goatables.html. [Accessed 9 July 2013]

Paolo Neirotti AD (2014) Current trends in smart city initiatives: some stylised facts. Cities 38(Jun): 25-36.

Phua GL (2007) Urbanization and slum formation. Journal of Urban Health: Bulletin of the New York Academy of Medicine 84(1): 27-34.

Planning Commission Government of India (2013) Twelfth five year plan (2012-2017) faster, more inclusive and sustainable growth. ${ }^{\text {st }}$ Edition. India: SAGE Publications Pvt Ltd. 
Pratap Podode FP (2016) Smart cities India readiness guide. Smart Cities Council. Retrieved from: https://smartnet.niua.org/sites/default/files/resources/Smart_Cities_ Council_India_Readiness_Guide_v2016-02.pdf.

Rajkumar Joshi SA (2016) Status and challenges of municipal solid waste management in India: a review. Cogent Environmental Science 2(1): 1139434.

Rita Yi ML (2013) The usage of automation system in smart home to provide a sustainable indoor environment: a content analysis in Web 1.0. International Journal of Smart Home 7(4): 47-60.

Rita Yi Man Li HD (2015) Sustainable construction waste management in Australia: a motivation perspective. In RY Li (ed.), Construction Safety and Waste ManagementAn Economic Analysis, 1-30. Springer.

Royal HaskoningDHV (2015) Corporation of the city of Panaji: final city sanitation plan. Noida: HaskoningDHV Consulting Private Limited.

Sang Keon Lee HR (2016) International case studies of smart cities - Singapore. InterAmerican Development Bank.

Sudhir Vyankatesh Wanmali DO (2018) Goa State, India. Retrieved from: https://www.britannica.com/place/Goa. [Accessed 19 July 2018]

Tame R (2014) Role of Panchayati Raj institutions in rural development:the study of a tribal village in Arunachal Pradesh. Modern Research Studies: An International Journal of Humanities and Social Sciences 1(3): 503-521.

Tata Communications (2018) Smart cities:the future of digital India. Retrieved from: https://www.tatacommunications.com/wp-content/uploads/2017/06/Tata-

Communications-Smart-Cities.pdf. [Accessed 29 May 2018]

The Statistics Portal (2018) India: degree of urbanization from 2007 to 2017. The Statistics Portal.

The Times of India (2016) SPV to implement Panaji smart city plan announced. Retrieved from: https://timesofindia. indiatimes.com/city/goa/SPV-to-implement-Panaji-SmartCity-plan-announced/articl eshow/53746637.cms. [Accessed 17 May 2018]

The Times of India (2017) Saligao garbage treatment plant begins generating power. Retrieved from: https://timesofindia.indiatimes.com/city/goa/saligao-garbagetreatment-plant-begins-generating-power/articleshow/5660721 8.cms. [Accessed 10 June 2018]

Tripathi P (2018). Sustainable cities, human mobility and international migration. Commission on Population and Development. Retrieved from: http://www.un.org/en/development/desa/population/pdf/commission/2018/country/A gendaItem3/en_india.pdf. [Accessed 18 June 2018]

United Nations (2015) World urbanization prospects: the 2014 revision. Department of Economic and Social Affairs/Population Division, United Nations.

Vajda Z (2017) Developing 100 smart cities in India. Retrieved from: http://www.geopolitika.hu/en/2017/11/17/developing-100-smart-cities-in-india/. [Accessed 20 June 2018]

World Bank (2011) Facts: urbanisation in India. Retrieved from: http://web.worldbank.org/archive /website01291/ WEB/ 0_CO-22.HTM. [Accessed 20 June 2018]

World Economic Forum (2015) Future of urban development and services. Retrieved from: https://www.weforum.org/events/national-strategy-day-india. [Accessed 13 June 2018]

Yigitcanlar T (2015) Smart cities: an effective urban development and management model? Australian Planner 52(1): 27-34. 
Vol. 7, No. 1 Goel \& Thomas: Outcomes from Building Transparency in Governance...

Zeneli V (2014) The role of institutions and good governance for attracting foreign direct investments: evidence from Southeast Europe. Business and Economics Journal 5(2): $1-20$.

Zeng DZ (2012) China's special economic zones adn industrial clusters: the engines for growth. Journal of International Commerce, Economics and Policy 3(3): 1-10. 